\title{
The Effect of Overweight on the Risk of Recurrence in Tunisian Patients with Operable Breast Cancer
}

\author{
Inès Ayadi Masmoudi ${ }^{1}$, Amine Masmoudi ${ }^{1}$, Nabil Toumi ${ }^{1}$, Afef Khanfir ${ }^{1}$, Mounir Frikha ${ }^{1}$, \\ Jamel Daoud ${ }^{2}$
}

${ }^{1}$ Department of Medical Oncology; ${ }^{2}$ Department of Radiation Oncology, Habib Bourguiba University Hospital, Sfax, Tunisia. Email: inesmaj@yahoo.fr

Received May $3^{\text {rd }}, 2011$; revised June $22^{\text {nd }}, 2011$; accepted July $1^{\text {st }}, 2011$.

\begin{abstract}
Obesity is associated with worse breast cancer outcomes in Western and Asian women. The present study was to determine the relation of body mass index (BMI) to disease-free survival (DFS) in Tunisian patients with operable breast cancer. We retrospectively reviewed data from 227 patients with operable breast cancer treated with primary surgery and adjuvant epirubicin-based chemotherapy. Patients were categorized into lower-BMI $\left(<27.5 \mathrm{~kg} / \mathrm{m}^{2} ; N=114\right) v$ higher-BMI $\left(>27.5 \mathrm{~kg} / \mathrm{m}^{2} ; N=113\right)$. Patients' and disease characteristics, including tumor size and lymph node status, were similar between the 2 groups. With a median follow-up of 56 months, there were 42 and 30 DFS events in the lower- and higher-BMI group, respectively (adjusted hazard ratio $(H R)$ : $0.74 ; 95 \% C I, 0.43$ to $1.26 ; p=0.26$ ). A significant interaction $(p<0.001)$ was found between BMI category and time, with a significant DFS advantage for the higher-BMI group after 3 years (adjusted HR: $0.28 ; 95 \%$ CI, i to $0.86 ; p=0.03$ ). We conclude that overweight is associated with a decreased risk of late recurrence in Tunisian patients with operable breast cancer.
\end{abstract}

Keywords: Adjuvant Chemotherapy, Early Breast Cancer, Obesity, Recurrence, Tunisia

\section{Introduction}

In Tunisia, breast cancer is the leading female cancer with an adjusted incidence of 30 per 100,000 per year [1]. Although patients with operable disease account for approximately two thirds of the cases, they usually present with large tumors and/or lymph node involvement [2], thus requiring a multimodality therapeutic approach.

In another hand, overweight, defined by a body mass index (BMI) higher than $25 \mathrm{~kg} / \mathrm{m}^{2}$, is a common problem among Tunisian women, with a prevalence of $51 \%$, and the half of them being obese (BMI $>30 \mathrm{~kg} / \mathrm{m}^{2}$ ) [3]. During the last two decades, a growing amount of literature had demonstrated a negative impact for overweight at diagnosis on the outcome of breast cancer [4]. The prognostic value of high BMI was consistently reported in various settings, including post-menopausal and premenopausal patients, early stage and locally-advanced disease, and different ethnic groups, mainly Caucasians and Asians [5-9]. Whether such correlation exists in North-African women with breast cancer is not documented.
In this context, the present study aimed to investigate the relation of BMI to the outcome in a cohort of Tunisian women with operable breast cancer uniformly treated with primary surgery followed by epirubicinbased adjuvant chemotherapy.

\section{Patients and Methods}

Between January 1995 and December 2005, 322 patients with operable breast carcinoma received adjuvant epirubicin-based chemotherapy in our centre. Information on weight and height at diagnosis was available for $227 \mathrm{pa}-$ tients, who form the basis for this retrospective study.

Operable breast cancer was defined as clinical T0-3N0-1 or T4b N0-1 disease with limited skin involvement. A baseline negative staging work-up including chest X-ray, liver ultra sonography and bone scan was mandatory for all patients, regardless of clinical stage. Primary surgery consisted of radical modified mastectomy or breast-sparing operation, with axillary lymph node dissection.

All patients received adjuvant chemotherapy, which 
was mandated by the presence of one or more of the following risk factors: age $<35$, pathological tumor size $>2$ $\mathrm{cm}$, lymph node involvement, negative hormone receptor status, histological grade 2 or 3 . Radiotherapy was indicated after chemotherapy in the presence of any of the following: breast-conserving surgery, lymph node involvement, clinical stage T3 or T4b, multifocal/multicenter tumor, or microscopic positive margins (R1 resection). For patients with hormone-receptor positive disease, tamoxifen $20 \mathrm{mg}$ daily was given regardless of menopausal status.

BMI at diagnosis, calculated as the weight $(\mathrm{kg})$ divided by the height $(\mathrm{m})$ squared, was dichotomised above and below the median value. The comparison between higher-BMI (BMI-H) and lower-BMI (BMI-L) groups was performed using Wilcoxon rank sum test for continuous variables, and khi-square or Fisher exact test, as appropriate, for categorical variables. Variables with $p$-values $<0.20$ were considered of borderline significance and were included as covariates for subsequent analyses. We used the Kaplan-Meier method to compute survival plots. DFS was defined as the time from surgery until relapse (local or distant), contralateral breast cancer or death, whichever occurred first. OS was calculated from surgery until death from any cause or last follow-up. We performed a Cox regression that adjusted for patients' characteristics that were different $(p<0.20)$ between the two groups to calculate hazard ratios (HR) for DFS between BMI-H and BMI-L groups. To test the interaction between BMI category and time, we compared the effect of BMI on DFS in two consecutive time intervals using a piecewise Cox regression model.

\section{Results}

\subsection{Patients' and Disease Characteristics}

Median age at diagnosis was 48 (range: 24 - 75). Among 162 patients for whom findings from initial physical examination were known, the majority had stage II or stage III disease (65\% and $32 \%$, respectively). Among $216(97 \%)$ patients with available information for hormone receptor status, estrogen and/or progesterone receptors were positive in $134(62 \%)$ of the cases. As it can be seen in Table 1, most patients had histologic grade 2 or $3(87 \%)$ ductal infiltrating carcinoma $(86 \%)$, with a tumor size $>2 \mathrm{~cm}(70 \%)$ and lymph node involvement $(60 \%)$.

According to the World Health Organisation (WHO) classification, 85 patients had grade 1 overweight (BMI between 25 and $29.9 \mathrm{~kg} / \mathrm{m}^{2}$ ) and 76 were obese (BMI $\geq$ $30 \mathrm{~kg} / \mathrm{m}^{2}$ ), for a total overweight rate of $71 \%$. Sixty two $(27 \%)$ patients were in the normal BMI range, while the remaining $4(2 \%)$ patients were in the lowest BMI cate-
Table 1. Patients and disease characteristics.

\begin{tabular}{|c|c|c|c|}
\hline & & BMI & \\
\hline & $\begin{array}{c}<27.5 \mathrm{~kg} / \mathrm{m}^{2} \\
(\mathrm{~N}=114) \\
\mathrm{N}(\%)\end{array}$ & $\begin{array}{c}\geq 27.5 \mathrm{~kg} / \mathrm{m}^{2} \\
(\mathrm{~N}=113) \\
\mathrm{N}(\%)\end{array}$ & $p$-value \\
\hline \multicolumn{4}{|l|}{ Age } \\
\hline Mean & 48 & 50 & $0.193^{\pi}$ \\
\hline$\leq 34$ & $11(10)$ & $7(6)$ & \\
\hline $35-49$ & $56(49)$ & $50(44)$ & \\
\hline$\geq 50$ & 47 (41.2) & $56(50)$ & \\
\hline Menopausal status* & & & 0.017 \\
\hline Pre/peri-menopausal & $62(61)$ & $44(44)$ & \\
\hline Post-menopausal & $40(39)$ & $56(56)$ & \\
\hline Unknown & 12 & 13 & \\
\hline Histological type & & & 0.803 \\
\hline Infiltrating ductal & $99(87)$ & $97(86)$ & \\
\hline Infiltrating lobular & $6(5)$ & $7(6)$ & \\
\hline Mixed carcinoma & $6(5)$ & $4(4)$ & \\
\hline Other & $3(3)$ & $5(4)$ & \\
\hline Tumor size (pT)* & & & 0.359 \\
\hline$\leq 2 \mathrm{~cm}$ & $37(34)$ & $28(26)$ & \\
\hline$>2 \mathrm{~cm}$ but $\leq 5 \mathrm{~cm}$ & $59(55)$ & $68(64)$ & \\
\hline$>5 \mathrm{~cm}$ & $12(11)$ & $10(9)$ & \\
\hline Unknown & 6 & 7 & \\
\hline Positive nodes & & & 0.204 \\
\hline 0 & $41(36)$ & $50(44)$ & \\
\hline 1 to 3 & $41(36)$ & $42(37)$ & \\
\hline$\geq 4$ & $32(28)$ & $21(19)$ & \\
\hline Histologic grade* & & & 0.219 \\
\hline 1 & $11(11)$ & $16(15)$ & \\
\hline 2 & $57(54)$ & $46(43)$ & \\
\hline 3 & $37(35)$ & $46(43)$ & \\
\hline Unknown & 9 & 5 & \\
\hline Hormone receptors* & & & 0.115 \\
\hline Positive & $62(57)$ & $72(67)$ & \\
\hline Negative & $47(43)$ & $35(33)$ & \\
\hline Unknown & 5 & 6 & \\
\hline Type of surgery & & & 0.394 \\
\hline Mastectomy & $93(82)$ & $87(77)$ & \\
\hline Breast-sparing & $21(18)$ & $26(23)$ & \\
\hline Chemotherapy & & & 0.404 \\
\hline FEC50/60 & $78(68)$ & $83(74)$ & \\
\hline FEC100 & $36(32)$ & $30(27)$ & \\
\hline Radiotherapy & & & 0.683 \\
\hline Yes & $99(87)$ & $96(85)$ & \\
\hline No & $15(13)$ & $17(15)$ & \\
\hline Endocrine therapy & & & 0.518 \\
\hline Tamoxifen & $40(58)$ & $41(53)$ & \\
\hline Tamoxifen then AI & $26(38)$ & $31(40)$ & \\
\hline Up-front AI & $0(0)$ & $2(3)$ & \\
\hline OS/OA alone & $2(3)$ & $1(1)$ & \\
\hline None & $1(1)$ & $3(4)$ & \\
\hline
\end{tabular}

${ }^{\uparrow}$ Wilcoxon rank sum test; * Percentages were calculated among patients for whom information on studied variable was available, Abbreviation: AI: aromatase inhibitor, OS/OA: ovarian suppression/ ovarian ablation

gory $\left(<18.5 \mathrm{~kg} / \mathrm{m}^{2}\right)$.

Median BMI value was $27.5 \mathrm{~kg} / \mathrm{m}^{2}$. Compared with those whom BMI was above the median, leaner patients tended to be younger, more likely to be pre- or peri-menopausal, and more likely to have hormone-unresponsive tumors $(0.05<p<0.20)$. Other disease characteristics, including tumor size and lymph node involvement, did not significantly differ between the two groups (Table 1). 


\subsection{Treatment}

Surgery consisted of total mastectomy in the majority (79\%) of the patients. Radiotherapy was given in $88 \%$ and $100 \%$ of the cases after mastectomy and breastsparing surgery, respectively. All patients underwent fluoro-uracil, epirubicin and cyclophosphamide (FEC) adjuvant chemotherapy, with varying epirubicin doses $\left(50,60\right.$ or $\left.100 \mathrm{mg} / \mathrm{m}^{2}\right)$. No statistically-significant differences were found between the two BMI groups with respect to treatment modalities (Table $\mathbf{1}$ ).

\subsection{Survival Outcomes}

At a median follow-up of 56 months, 5-year DFS for the entire cohort was $70 \%$. DFS and OS events in each BMI group are summarised in Table 2.

There was a non-statistically significant $6 \%$ absolute difference between the two BMI groups in terms of DFS, with a 5 -year DFS of $73 \%$ and $67 \%$ for the BMI-H and BMI-L groups, respectively (HR for BMI-H versus BMI-L: $0.72 ; 95 \%$ CI, 0.45 to 1.15 ; log-rank $p=0.17$ ) (Figure 1(a)). Comparable results were found after adjusting for age, menopausal status and hormone-receptor status ( $\mathrm{HR}=0.70 ; 95 \% \mathrm{CI}, 0.41$ to 1.18$)$. The rate of overall survival (OS) at 5 years was $82 \%$ in the higher-BMI group and $77 \%$ in the lower-BMI group (HR $=1.00,95 \% \mathrm{CI}, 0.57$ to 1.79 ; log-rank $p=0.98)($ Figure 1(b)).

On the basis on Figure 1(a), we analysed DFS using a piecewise Cox regression with change point at 3 years. There was a statistically significant interaction between BMI category and time $(p<0.001)$, implying that the effect of BMI changes across time. Within the first 3 years, the adjusted HR for DFS between BMI-H and BMI -L groups was 1.13 (95\% CI, 0.59 to 2.15 ). After 3 years, the likelihood of a DFS event was nearly 4 fold lower for the BMI-H group compared with the BMI-L group $(\log$-rank $p=0.03$; adjusted $\mathrm{HR}=0.28 ; 95 \% \mathrm{CI}$, 0.09 to 0.84 ).

The unadjusted HR for DFS between BMI-H and BMI-L groups in various patients subgroups are shown in Table 3. No significant interaction was found between BMI and any of the patients' and disease characteristics analysed ( $p$ values not shown).

\section{Discussion}

Unexpectedly, the present study shows that overweight is not associated with advanced tumor stage or lymph node involvement at diagnosis in Tunisian women with operable breast cancer. Moreover, a major finding from our study is that overweight is associated with a reduced risk of late recurrence. In view of the existing evidence demonstrating a negative effect of overweight on breast can-
Table 2. Disease-free survival events summary.

\begin{tabular}{lcc}
\hline & $\begin{array}{c}\mathrm{BMI}<27.5 \mathrm{~kg} / \mathrm{m}^{2} \\
(\mathrm{~N}=114)\end{array}$ & $\begin{array}{c}\mathrm{BMI}>27.5 \mathrm{~kg} / \mathrm{m}^{2} \\
(\mathrm{~N}=113)\end{array}$ \\
\hline Recurrence & 25 & 19 \\
Distant only & 11 & 7 \\
Both distant and local & 5 & 2 \\
Local only & 1 & 1 \\
Contralateral & & \\
Death & 25 & 22 \\
After recurrence & 0 & 1 \\
Without previous & & 30 \\
recurrence & \\
Total events & 42 & \\
\hline
\end{tabular}

Table 3. Hazard ratios for breast cancer recurrence by body mass index category.

\begin{tabular}{lcccc}
\hline & \multicolumn{2}{c}{ Overall } & \multicolumn{2}{c}{$>3$ years } \\
\hline & HR* & $95 \%$ CI & HR* & $95 \%$ CI \\
Age & & & & \\
$<50$ & 0.81 & $0.45-1.45$ & 0.54 & $0.18-1.59$ \\
$\geq 50$ & 0.60 & $0.27-1.35$ & 0.22 & $0.05-1.01$ \\
Menopausal status & & & & \\
$\begin{array}{l}\text { Pre/peri-menopausal } \\
\text { Post- menopausal }\end{array}$ & 0.83 & $0.43-1.60$ & 0.49 & $0.13-1.80$ \\
Hormone receptors & 0.59 & $0.24-1.43$ & 0.12 & $0.01-1.00$ \\
$\begin{array}{l}\text { Positive/unknown } \\
\text { Negative }\end{array}$ & 0.64 & $0.32-1.27$ & 0.39 & $0.12-1.25$ \\
Tumor size & 0.92 & $0.47-1.78$ & 0.45 & $0.12-1.71$ \\
$\leq 2$ cm & & & & \\
$>$ 2 cm & 0.37 & $0.08-1.73$ & 0.43 & $0.16-1.17$ \\
Lymph Node status & 0.70 & $0.41-1.21$ & 0.31 & $0.04-2.63$ \\
Negative & & & & \\
Positive & 0.60 & $0.23-1.59$ & 0.14 & $0.02-1.20$ \\
Histologic grade & 0.84 & $0.48-1.44$ & 0.61 & $0.23-1.62$ \\
Grade 1/2 & & & & \\
Grade 3 & 0.64 & $0.32-1.26$ & 0.45 & $0.14-1.42$ \\
\hline
\end{tabular}

*Unadjusted hazard ratio of higher- to lower-body mass index. Abbreviation: $H R$, hazard ratio.

cer patients' DFS and OS, our results are seemingly surprising.

In view of reported association between increased body weight at diagnosis and advanced disease, it has been hypothesised that the higher exposure to endogenous estrogens mediated by adipose tissue may explain the prognostic effect of obesity. In our study, tumor stage and lymph node involvement were similar between BMI-H and BMI-L groups. One may argue that the difference in DFS may be due to the fact that more BMI-H patients had hormone-receptor positive disease. However, the effect of overweight was not modified after adjustment for hormone receptor status.

It has been suggested that the effect of obesity on breast cancer outcomes may be mediated by leptin, a neuroendocrine hormone linked to obesity [10]. However, elevated levels of leptin were not associated with outcome in 471 women with operable breast cancer [11]. Recently, a Tunisian group investigated the prognostic value of polymorphisms in leptin gene 5' promoter region, 


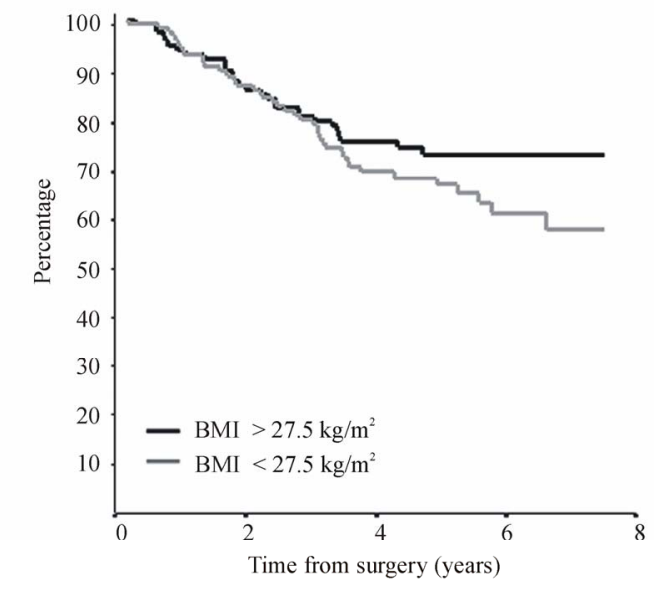

No.at risk

$\mathrm{BMI}>27.5 \quad 113 \quad 106 \quad 96 \quad 87 \quad 65 \quad 41 \quad 21 \quad 7$

BMI $<27.5 \quad 114 \quad 108 \quad 98 \quad 87 \quad 64 \quad 46 \quad 24 \quad 15$

(a)

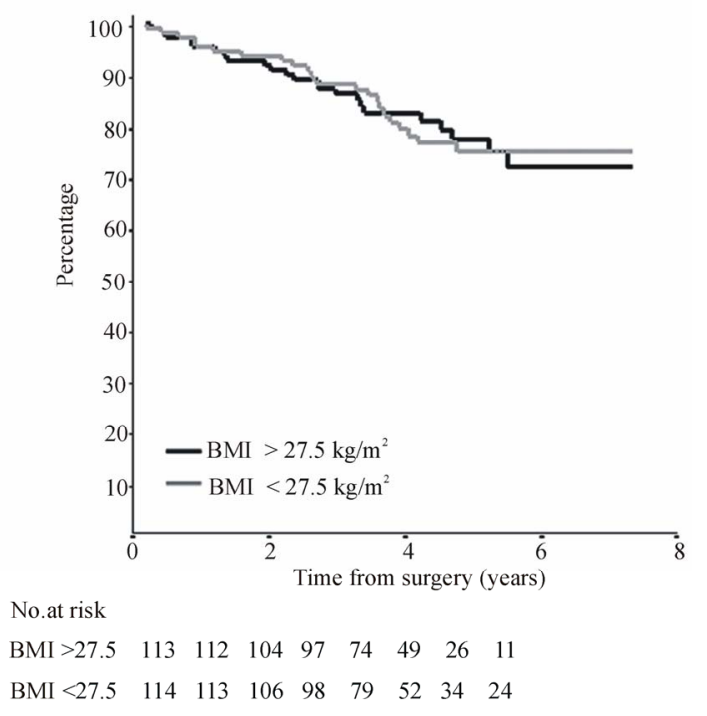

(b)

Figure 1. Kaplan-Meier estimates of (a) disease-free survival and (b) overall survival according to body mass index.

and found a decreased DFS in breast carcinoma patients with the 2548A allele [12]. In another hand, it had been shown that the genotype $2548 \mathrm{G} / \mathrm{A}$ is significantly associated with obesity, compared with the homozygous $\mathrm{G} / \mathrm{G}$ genotype [13]. Taken together, the results of these two studies suggest that the risk of breast cancer recurrence is increased in obese patients, which is in opposition with our findings. Nonetheless, the report by Snoussi et al. [12] was limited by patients' heterogeneity for disease and treatment characteristics and the loss of leptin gene polymorphism prognostic value after multivariate analysis. Thus, this study should be only regarded as hypothesis-generating and further research is needed to properly assess the prognostic value of leptin and its receptor in Tunisian breast cancer patients.

Although our findings are in contrast with published literature with respect to the relation of overweight to early breast cancer outcomes, it is interesting to note that results similar to ours have been reported in patients with inflammatory breast cancer (IBC). Indeed, in a single-institution study of 100 Tunisian women with IBC, mostly pre-menopausal, the 3 -year progression-free survival was $15 \%, 21 \%$ and $34 \%$ in normal, overweight and obese patients, respectively [14]. Similarly, in a report from the M.D. Anderson group, long-term OS was approximately doubled in pre-menopausal obese patients with IBC compared with their leaner counterparts. Of note, as in our study, survival curves were overlapping during the first 3 years of follow-up, but did clearly separate thereafter [15].

One of the key biologic features of IBC is the over expression of RhoC GTPase (RhoC), which is thought to be responsible of the high aggressiveness of the disease [16]. Interestingly, weight gain is associated with increased expression of caveolin-1 [17], and caveolin-1 inhibits RhoC activation and subsequent p38 MAPK pathway [18]. Another major component of the "inflammatory signature" is the insulin-like growth factor (IGF) pathway, which promotes invasion and metastasis $[19,20]$. Interestingly, in a recently reported large study, obese women had lower circulating levels of IGF-1 than their counterparts with normal range BMI [21]. Thus, both RhoC-Caveolin-1 and IGF-1 pathways may account for the favourable prognostic effect of overweight in IBC. But how would this apply to patients with operable breast cancer?

Tunisian patients with breast cancer have fewer grade 1 and fewer hormone-responsive tumors then their counterparts from Western countries [22]. High grade and low endocrine responsiveness are typically encountered in IBC [23]. Moreover, breast cancer incidence peaks in Tunisian women aged between 45 and 49 years, and shows a plateau thereafter [1], a figure that is remarkably similar to IBC in Western countries [24]. Taken together, these data suggest that operable breast cancer in Tunisian women may share major biologic features with IBC, thus resulting in similar effect of overweight on outcome.

One of the strengths of our study is the ethnic homogeneity of our patients and the uniformity of loco-regional and systemic treatment. A baseline work-up was systematically performed, thus excluding patients with unsuspected distant metastasis, albeit such practice is not currently recommended for patients with stage II breast cancer [25]. Therefore, we had an excellent opportunity to assess the prognostic value of overweight with minimal effect of potential confounding parameters. 
Nonetheless, as with any study, our study has some limitations. The relatively small number of patients and short follow-up made it difficult to detect a difference in OS between BMI groups. Moreover, our analysis was based on BMI dichotomization on its median rather than WHO-defined BMI categories. However, the relevance of WHO-defined BMI categories to non-European populations has been questioned [26], and remains to be proved in North African population.

\section{Conclusions}

A negative impact for overweight at diagnosis on the outcome of breast cancer has been demonstrated in the literature. In our study, we found an inverse correlation between overweight and the risk of recurrence in Tunisian women with operable breast cancer. Another finding in contrast with previous literature was the lack of association between obesity and disease stage at presentation, reinforcing the hypothesis of a biologically different disease. International partnership is urgently needed to promote research aiming to study the molecular profile and identify cell pathways involved in breast carcinogenesis in Tunisian women.

\section{REFERENCES}

[1] M. Ben Abdallah, S. Zehani, M. Maalej, M. Hsairi, M. Hechiche, K. Ben Romdane, H. Boussen, A. Saadi, N. Achour and F. Ben Ayed, "Cancer du sein en Tunisie: Carctéristiques Epidémiologiques et Tendance Evolutive de l'Incidence, " Tunisie Médicale, Vol. 87, No. 7, 2009, pp. 417-425.

[2] A. Khanfir, M. Frikha, F. Kallel, M. Meziou, K. Trabelsi, T. Boudawara, J. Mnif and J. Daoud, "Le Cancer du sein de la Femme Jeune Dans le sud Tunisien," Cancer Radiother, Vol. 10, No. 8, 2006, pp. 565-571. doi:10.1016/j.canrad.2006.09.115

[3] N. Mokhtar, J. Elati, R. Chabir, A. Bour, K. Elkari, N. P. Schossman, B. Caballero and H. Aguenaou, "Diet Culture and Obesity in Northern Africa," Journal of Nutrition, Vol. 131, No. 3, 2001, pp. 887S-892S.

[4] J. J. Dignam and E. P. Mamounas, "Obesity and Breast Cancer Prognosis: An Expanding Body of Evidence," Annals of Oncology, Vol. 15, No. 6, 2004, pp. 850-851. doi:10.1093/annonc/mdh241

[5] International Breast Cancer Study Group, G. Berclaz, S. Li, K. N. Price, A. S. Coates, M. castiglione-Gertsch, C. M. Denstam, S. B. Holmberg, J. Lindtner, D. Erzen, J. Collins, R. Synder, B. Thurlimann, M. F. Fey, C. Mendiola, I. D. Werner, E. Simoncini, D. Crivellari, R. D. Gelber and A. Goldhirsch, "Body Mass Index as a Prognostic Feature in Operable Breast Cancer: The International Breast Cancer Study Group Experience," Annals of Oncology, Vol. 15, No. 6, 2004, pp. 875-884. doi:10.1093/annonc/mdh222

[6] S. Loi, R. L. Milne, M. L. Friedlander, M. R. E. McCre- die, G. G. Giles, J. L. Hopper and K. A. Phillipps, “Obesity and Outcomes in Premenopausal and Postm-enopausal Breast Cancer," Cancer Epidemiology, Biomarkers \& Prevention, Vol. 14, No. 7, 2005, pp. 1686-1691.

doi:10.1158/1055-9965.EPI-05-0042

[7] P. E. Abrahamson, M. D. Gammon, M. J. Lund, E. W. Flagg, P. L. Porter, J. Stevens, S. A. Swanson, L. A. Brinton, J. W. Eley and R. J. Coates, "General and Abdominal Obesity and Survival among Young Women with Breast Cancer," Cancer Epidemiology, Biomarkers \& Prevention, Vol. 15, No. 10, 2006, pp. 1871-1877. doi:10.1158/1055-9965.EPI-06-0356

[8] S. Dawood, K. Broglio, A. M. Gonzalez-Angulo, S. W. Kau, R. Islam, G. N. Hortobagyi and M. Cristofanilli, "Prognostic Value of Body Mass Index in Locally Advanced Breast Cancer," Clinical Cancer Research, Vol. 14, No. 6, 2008, pp. 1718-1725. doi:10.1158/1078-0432.CCR-07-1479

[9] M. H. Tao, X. O. Shu, Z. X. Ruan, Y. T. Gao and W. Zheng, "Association of Overweight with Breast Cancer Survival," American Journal of Epidemiology, Vol. 163, No. 2, 2006, pp. 101-107. doi:10.1093/aje/kwj017

[10] D. P. Rose, E. M. Gilhooly and D. W. Nixon, "Adverse Effects of Obesity on Breast Cancer Prognosis, and the Biological Actions of Leptin (Review)," International Journal of Oncology, Vol. 21, No. 6, 2002, pp. 12851292.

[11] P. J. Goodwin, M. Ennis, I. G. Fantus, K. I. Pritchard M. E. Trudeau, J. Koo and N. Hood, "Is Leptin a Mediator of Adverse Prognostic Effects of Obesity in Breast Cancer?" Journal of Clinical Oncology, Vol. 23, No. 25, 2005, pp. 6037-6042. doi:10.1200/JCO.2005.02.048

[12] K. Snoussi, A. D. Strosberg, N. Bouaouina, S. Ben Ahmed, A. N. helal and L. chouchane, "Leptin and Leptin Receptor Polymorphisms Are Associated with Increased Risk and Poor Prognosis of Breast Carcinoma," BMC Cancer, Vol. 20, 2006, pp. 6-38.

[13] M. F. Mnif, A. Zouari, S. Sessi, M. Elleuch, M. Fourati, K. Makni, N. Charfi and M. Abid, "Association du Polymorphisme G-2548 A de la Région 5 du Gène de la Leptine avec l'Obésité dans la Région de Sfax en Tunisie," Diabetes Metabolism, Vol. 35, No. S1, 2009, pp. 56-57. doi:10.1016/S1262-3636(09)71920-2

[14] S. I. Labidi, K. Mrad, A. Mezlini, M. Ayadi Warda, J. D. Coombs, M. Ben Abdallah, K. Ben Romdhane, P. Viens and F. Ben Ayed, "Inflammatory Breast Cancer in Tunisia in the Era of Multimodality Therapy," Annals of Oncology, Vol. 19, No. 3, 2008, pp. 473-480. doi:10.1093/annonc/mdm 480

[15] S. Chang, J. R. Alderfer, L. Asmar and A. U. Buzdar, "Inflammatory Breast Cancer Survival: The Role of Obesity and Menopausal Status at Diagnosis," Breast Cancer Research and Treatment, Vol. 64, No. 2, 2000, pp. 157 163. doi:10.1023/A:1006489100283

[16] K. L. Van Golen, Z. F. Wu, X. T. Qiao, L. W. Bao and S. D. Merajver, "RhoC GTPase, a Novel Transforming Oncogene for Human Mammary Epithelial Cells That Par- 
tially Recapitulates the Inflammatory Breast Cancer Phenotype," Cancer Research, Vol. 60, No. 20, 2000, pp. 5832-5838.

[17] P. Singh, T. E. Peterson, A. Romero-Corral, D. E. Davidson, M. D. Jensen and V. K. Somers, "Identification of Caveolin-1 as an Inhibitor of Leptin Signaling: Implications for Leptin Resistance in a Human Weight Gain Model," Circulation, Vol. 118, 2008, p. S278.

[18] M. Lin, M. M. DiVito, S. D. Merajver, M. Boyanapalli and K. L. Van Golen, "Regulation of Pancreatic Cancer Cell Migration and Invasion by RhoC GTPase and Caveolin-1," Molecular Cancer, Vol. 4, 2005, pp. 4-21. doi:10.1186/1476-4598-4-21

[19] S. Van Laere, I. Van der Auwera, G. Van den Eynden, P. Van Hummelen, P. Van Dam, E. Van Marck, P. B. Vermeulen and L. Dirix, "Distinct Molecular Phenotype of Inflammatory Breast Cancer Compared to Non-Inflammatory Breast Cancer Using Affymetrix-Based Genome-Wide Gene-Expression Analysis," British Journal of Cancer, Vol. 97, No. 8, 2007, pp. 1165-1174. doi:10.1038/sj.bjc. 6603967

[20] X. Zhang, M. Lin, K. L. Van Golen, K. Yoshioka, K. Itoh and D. Yee, "Multiple Signalling Pathways Are Activated during Insulin-Like Growth Factor-I (IGF-I) Stimulated Breast Cancer Cell Migration," Breast Cancer Research and Treatment, Vol. 93, No. 2, 2005, pp. 159-168. doi:10.1007/s10549-005-4626-8

[21] I. T. Gram, T. Norat, S. Rinaldi, L. Dossus, A. Lukanova, B. Tehard, F. Clavel-Chapelon, C. H. Van Gils, P. A. H. Van Noord, P. H. M. Peeters, H. B. Bueno-De-Mesquita, G. Nagel, J. Linseisen, P. H. Lahamann, H. Boeing, D. Palli, C. Sacerdote, S. Panico, R. Tumino, S. Sieri, M. Dorronsoro, J. R. Quiros, C. A. Navarro, A. Barricarte, M. J. Tormo, C. A. Gonzalez, K. Overvad, S. P. Johnsen, A. Olsen, A. Tjonneland, R. Travis, N. Allen, S. Bingham, K. T. Khaw, P. Stattin, A. Trichopoulou, C. Casagrande, E.
Riboli and R. Kaaks, "Body Mass Index, Waist Circumference and Waist-Hip Ratio and Serum Levels of IGF-I and IGFBP-3 in European Women," International Journal of Obesity (Lond), Vol. 30, No. 11, 2006, pp. 1623-1631. doi:10.1038/sj.ijo.0803324

[22] L. Ayadi, A. Khabir, H. Amouri, S. Karray, A. Dammak, M. Guermazi and T. Boudawara, "Correlation of HER-2 over-Expression with Clinico-Pathological Parameters in Tunisian Breast Carcinoma," World Journal of Surgical Oncology, Vol. 6, No. 1, 2008, p. 112. doi:10.1186/1477-7819-6-112

[23] E. Charafe-Jauffret, K. Mrad, S. Labidi, A. Ben Hamida, K. Ben Romdhane, M. Ben Abdallah, C. Ginestier, B. Esterni, D. Birnbaum, F. Ben Ayed, L. Xerri, A. Mezlini and J. Jacquemier, "Inflammatory Breast Cancers in Tunisia and France Show Similar Immunophenotypes," Breast, Vol. 16, No. 4, 2007, pp. 352-358. doi:10.1016/j.breast.2007.01.002

[24] K. W. Hance, W. F. Anderson, S. S. Devesa, H. A. Young and P. H. Levine, "Trends in Inflammatory Breast Carcinoma Incidence and Survival: The Surveillance, Epidemiology, and End Results Program at the National Cancer Institute," Journal of the National Cancer Institute, Vol. 97, No. 13, 2005, pp. 966-975. doi:10.1093/jnci/dji172

[25] F. Puglisi, A. Follador, A. M. Minisini, G. G. Cardellino, S. Russo, C. Andreetta, S. Di Terlizzi and A. Piga, "Baseline Staging Tests after a New Diagnosis of Breast Cancer: Further Evidence of Their Limited Indications," Annals of Oncology, Vol. 16, No. 2, 2005, pp. 263-266. doi:10.1093/annonc/mdi063

[26] S. Low, M. C. Chin, S. Ma, D. Heng, M. Deurenberg-Yap, et al., "Rationale for Redefining Obesity in Asians," Annals Academy of Medicine Singapore, Vol. 38, No. 1, 2009, pp. 66-69. 